\title{
Population dynamics of the pioneer population of Daphnia parvula, Fordyce during the invasion of Lake Candia (Northern Italy)
}

\author{
Nicoletta RICCARDI*, Gianluigi GIUSSANI, Fiorenza MARGARITORA ${ }^{1)}$ and Bruno COUCHAUD \\ CNR Istituto per lo Studio degli Ecosistemi, Largo V. Tonolli 50, I-28922 Verbania Pallanza, Italy \\ ${ }^{1)}$ Dip. di Biologia Animale e dell’Uomo, Università degli Studi di Roma La Sapienza, V.le dell'Università 32, 00185 Roma, Italy \\ *e-mail corresponding author: n.riccardi@ise.cnr.it
}

\begin{abstract}
Since the 1970s Daphnia parvula, Fordyce, originally distributed in the New World, has been invading Europe. In Italy D. parvula first appeared in the shallow, eutrophic Lake Candia (Piedmont, Northern Italy) during September 2002. Although several studies have documented D. parvula dispersal in European habitats, little is known about the life cycle and ecology of this invader in its new habitats. Invasion success depends on the ability of the invader population to perform well in the new ecosystem, which in turn results from the interaction between the characteristics of the invader and those of the invaded environment and its resident community. Early detection of D. parvula in the intensively studied Lake Candia offered an excellent opportunity to study the performance of the pioneer population and to document the early phases of invasion. Following the dynamics of the pioneer D. parvula population provided evidence of a high level of gamogenetic reproduction during most periods of population development. The production of males started at the onset of population growth prior to ephippia formation. The sex ratio ranged from 0.1 to 0.33 males per female with a maximum in October when males accounted for up to $24 \%$ of the total population density. The percentage of ephippia (free ephippia + ephippial females) out of the total population density ranged from 3 to 23\%. The large pool of resting eggs produced by the pioneer population of D. parvula in Lake Candia might reflect a strategy for increasing the probability of survival and establishment in the new environment.
\end{abstract}

Key words: alien species, reproductive strategy, invertebrate predation, Chaoborus flavicans

\section{INTRODUCTION}

Colonization of new habitats is a natural process which increases the chance of species survival by extending the area of distribution and enhances speciation through founder effects and the differential survival of lineages adapted to specific habitats. The cosmopolitan distribution of many aquatic species and the rapid colonization of recently established water bodies demonstrate the importance of this natural phenomenon.

Invasion success strongly depends on the ability of the invader to adapt to critical environmental variables and to be successful in its interactions with the native species, i.e. conquering a niche through competition or exploiting a vacant niche.

Most of the invasions in freshwater ecosystems depend on the passive dispersal of propagules both by natural vectors (e.g. Jarnagin et al. 2000; Figuerola \& Green 2002; Bohonak \& Jenkins 2003) or through intentional or accidental transport associated with human activities (e.g. Dzialowski et al. 2000; Johnson et al. 2001; Grigorovich et al. 2003). The number of accidental introductions has considerably increased over the last decades (Hebert \& Cristescu 2002). The introduction and establishment of an invader cannot occur without effects on native communities and can profoundly modify ecosystem functioning (e.g. Vitousek 1986; Vitousek et al. 1996; Carlton 1996). Therefore, predicting the outcome of invasions and determining the qualities of successful invaders has long been a problem in ecology (e.g. Elton 1958; Ehrlich 1986; Pimm 1989; Bij de Vaate et al. 2002; Mc Mahon 2002). Abundant literature (reviewed by Bollens et al. 2002) exists on zooplankton invasions, dealing mostly with zoogeographic distribution, range extension or vectors and mechanisms of transport, while the biological and ecological characteristics of invading species are poorly studied. The ability to produce diapausing resting stages enhances species survival under critical conditions thus facilitating dispersal of aquatic organisms even over long distances and across geographic barriers. Moreover, the production and storage of egg banks can give a higher chance of invasion success (e.g. Panov et al. 2004).

This study deals with the invasion of Lake Candia by Daphnia parvula, a small species new to Italy, which was first introduced into SW Germany from North America during the 70s (Flössner \& Kraus 1976). Ephippia were probably transported by amphibian vehicles used by U.S. Army pioneer troops involved in the manoeuvres periodically carried out in the area (Unterfranken, SW Germany). The species has spread rapidly in Europe where it has colonized meso-eutrophic water bodies including small lakes, reservoirs, permanent ponds, canals and river meanders. (Coussement et al. 1976; Frenzel 1976; Einsle 1978, 1980; Armengol 1978; Schaber 1983; Hrbaček 1987; Herbst \& Anders 1987; Petkowski 1990; Flössner 2000). Until 2002, when it 
was recorded in Lake Candia (Northern Italy), the species had never been found found south of the Alps, which were traditionally considered a natural barrier to invasions. The most probable vectors for the introduction of the species to Lake Candia were waterbirds coming to the lake mainly from Germany and East Europe.

Apart from their distribution, very little ecological information about European populations is available (Flössner 2000). The purpose of this study was to follow the seasonal cycle and dynamics of the pioneer population of $D$. parvula in the attempt to identify species traits that may be useful for predicting invasion success and the potential for future range expansion.

\section{METHOD}

\subsection{Study site}

Lake Candia is a small $\left(1.49 \mathrm{~km}^{2}\right)$, shallow (maximum depth $=7.7 \mathrm{~m}$; mean depth $=3.8 \mathrm{~m}$ ) eutrophic water body located in the subalpine area near Turin (Piedmont, Northern Italy). Its most important water sources are internal springs, precipitation and runoff; the drainage area $\left(9.9 \mathrm{~km}^{2}\right)$ is mainly devoted to agriculture. To improve lake recovery after sewage diversion, biomanipulation was applied in 1986 and 1987, consisting of the removal of most of the rudd (Scardinius erythrophthalmus) biomass to reduce fish predation on zooplankton (Giussani et al. 1990; Giussani \& Galanti 1995). Continuous studies on the lake started in 1985; since then, variations in the abundance, species composition and structure of the zooplankton assemblage have been monitored at monthly or fortnightly intervals.

The fish assemblage of the lake consists mostly of the Cyprinidae $S$. erythrophthalmus, the Centrarchidae Micropterus salmoides, the Esocidae Esox lucius, and the Ictaluridae Ictalurus melas. The dominant zooplankton species in the lake are the copepods Eudiaptomus gracilis and Thermocyclops crassus, and among cladocerans a mixed population of Daphnia hyalina, $D$. cucullata and the hybrids $D$. hyalina $\times$ cucullata and $D$. hyalina $\times$ galeata. Other constant species are the copepods Cyclops vicinus, C. strenuus, Mesocyclops leuckarti, and the cladocerans Bosmina longirostris, Ceriodaphnia quadrangula, Diaphanosoma brachyurum, Chydorus sphaericus and Leptodora kindtii. The planktivorous larvae of Chaoborus flavicans are generally present from June to November-December, some years attaining a relatively high density (Riccardi et al. 2002). Daphnia parvula first appeared in September 2002.

\subsection{Sampling}

Since the first appearance of Daphnia parvula (September $10^{\text {th }}, 2002$ ) until its disappearance in December, zooplankton samples were obtained on average at 14 day intervals by vertical tows from the bottom to the surface with an open net of $126 \mu$ m mesh size. Each sample was obtained by pooling nine replicate hauls (corresponding to 1475 liters of filtered water) collected in three stations located along the major axis of the lake according to the direction of the prevailing winds. Each sample was concentrated using a $50 \mu \mathrm{m}$-mesh net and the animals killed by immersion in 95\% ethanol before preservation in a $5 \%$ neutralized $\left(\mathrm{CaCO}_{3}\right)$ formaldehyde solution. The use of alcohol prevents carapace ballooning and the loss of eggs/embryos from the brood pouch.

\subsection{Zooplankton analyses}

Daphnia parvula abundance was enumerated on at least 200 specimens per sample, except on September $10^{\text {th }}$ when only 82 individuals were found in the sample. The percentage of egg-bearing females relative to the total number of females was estimated from either 200 females or all the females present in a sample. The mean number of eggs per egg-bearing female was determined from at least 100 individuals. Individual lengths (from the top of the carapace to the base of the tailspine) were measured to the nearest $20 \mu \mathrm{m}$ with a calibrated ocular micrometer at 40×. Measurements were performed on 100 females, 100 reproductive females and 30-100 males when present, except on 10 September when all the individuals were measured.

The smallest adult size class (primipara) was determined as the size class in which at least $5 \%$ of the total number of egg bearing females were observed. The minimum amount of $5 \%$ ensured that the smallest adult size class would not be set by a single precociously reproducing female (Caramujo et al. 1997). The proportion of juveniles (JUV), adults with eggs (AD+) and adults without eggs (AD-) in each $0.1 \mathrm{~mm}$ size class were estimated from the size measurements.

Fecundity (F) was calculated as the average number of eggs per adult female. Egg development time, required to estimate birth rate (Paloheimo 1974), was calculated by the equation proposed by Saunders et al. (1999) for small Daphnia species:

$$
D_{e}=1 /\left(0.00038 T^{2}+0.013 T-0.0040\right)
$$

where $D_{e}$ is the temperature-dependent egg development time (days) for temperatures between 4 and $30{ }^{\circ} \mathrm{C}$. The temperature at which egg develpment occurred was determined by taking the average temperature from 0-6 $\mathrm{m}$ (weighted mean on the water column) at each sampling date.

The instantaneous rate of population increase ( $r$ in day $^{-1}$ ) was calculated as:

$$
r=\left(\ln N_{t}-\ln N_{0}\right) / t
$$

where $N_{0}$ is the population density at time zero and $N_{t}$ is the population density at time $t$, in days. This equation assumes exponential growth and no immigration. The instantaneous death rate was estimated from the difference between $b$ and $r$. 
We calculated absolute daily mortality $(M)$ for Daphnia parvula from the dynamics data according the equation:

$$
M_{(\mathrm{t} 1, \mathrm{t} 1+1)}=[d /(b-d)] \times N_{0} \times\left[e^{(\mathrm{b}-\mathrm{d})}-1\right]
$$

An estimated Chaoborus flavicans predation rate was obtained according to Krylov (1992) by applying the 'disc' equation (Holling 1959):

$$
P R=a^{\prime} N / 1+a^{\prime} T_{h} N
$$

where $P R$ is the predation rate (prey $\operatorname{pred}^{-1} \mathrm{~d}^{-1}$ ), $\mathrm{N}$ is the prey density (prey $\mathrm{l}^{-1}$ ), $T_{h}$ and $a^{\prime}$ are coefficients referred to as prey 'handling time' $(d)$ and 'attack rate' $\left(\mathrm{l} \mathrm{d}^{-1}\right)$.

The $a^{\prime}$ and $T_{h}$ parameters given by Krylov (1992) for small (0.77 mm size) daphnids and Daphnia parvula density for each sampling date were used in the calculation. An estimate of the daily food consumption of Chaoborus flavicans (with only Daphnia as possible prey) was obtained by multiplying the predation rate $(P R)$ by the predator density for each sample date. We used linear regression to describe the relationship between individual body length and clutch size for each sample date and for the pooled data of the whole period. Non-parametric Spearman correlation was used to correlate Daphnia body size with temperature and to correlate clutch size and egg ratio with chlorophyll concentration.

\section{RESULTS}

The seasonal variation of the Daphnia species during 2002 is illustrated in figure 1. Daphnia spp., represented by the $D$. hyalina $\times$ galeata complex and some rare $D$. cucullata, showed a spring peak in April, a summer decline and a maximum in late summer. Daphnia parvula appeared at the beginning of September, rapidly increased through October, attaining a maximum in early November, then sharply declined to disappear in December.

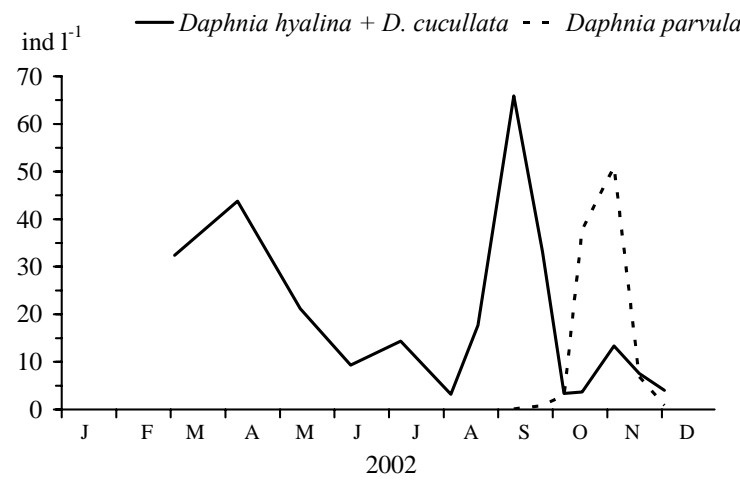

Fig. 1. Seasonal variation of population density of Daphnia parvula and native Daphnia species.

The population started on September $10^{\text {th }}$ with a few $\left(0.08\right.$ ind $\left.\mathrm{l}^{-1}\right)$ females presumably hatched from ephippia. Females of reproductive size (adult) were only $23 \%$ of the population but most of them (71\%) carried parthenogenetic eggs. The subsequent development of the population can be divided into different phases. A lag phase of slow increase lasting about one month preceded a sharp increase in juvenile females (Fig. 2a) which peaked in mid-October. Production of males, which had already started on September $26^{\text {th }}$, contributed to the phase of logarithmic growth, following the same pattern as juvenile females (Fig. 2b). A further increase in total density (which peaked on 5 November) was accounted for by an increased number of mature females (Fig. 2c), while juveniles gradually decreased (Fig. 2a). Adult aging and reduction of newborn production determined the decline of the population by mid-November through December.

The maximum birth rate (Fig. 2d) preceded the steep increase in juveniles and corresponded to the lag phase of population growth. The instantaneous rate of increase ( $r$ ) during this period was nearly constant with positive values lower than the potential rate of increase $(b)$. This unrealized potential population could reflect juvenile mortality in the first phase of adaptation to the new environment. Predation by late instar larvae of Chaoborus flavicans, which increased up to 0.35 ind $\mathrm{l}^{-1}$ between mid September and mid October (Fig. 3a), could have contributed to juvenile mortality. Indeed, estimates of the daily food consumption of Chaoborus flavicans (with only Daphnia as possible prey) largely exceeded Daphnia mortality in September-October (Fig. 3b), suggesting that predation could have affected Daphnia parvula dynamics in this period. Subsequently, predation did not account for the increased mortality, which was driven by other factors (e.g individual ageing).

The maximum $r$ value $(0.256)$ was attained during the log phase of population growth driven by juvenile female and male production, while the birth rate began to decrease. The resulting negative value of the death rate could be an effect of the contribution of newborns hatched from ephippia, or could be due to a sampling artifact, i.e. too long an interval between successive samples. The parthenogenetic egg stock did not account for the increase in juveniles. Birth rates continued to decrease as the total population density increased and were maintaned at positive but very low values during the phase of population decline. Positive and increasing values of death rates resulted from the decrease of $r$ values, which obviously became negative with the decrease in population.

Population changes were a clear result of variations in the size distribution and reproductive state of the females (Fig. 4). Population recruitment was evidenced by the abundance of individuals smaller than $500 \mu \mathrm{m}$, which increased from September $26^{\text {th }}$ to October $18^{\text {th }}$ and subsequently disappeared. Accordingly, an increasing proportion of females bearing eggs was observed in September-October in the size classes above $800 \mu \mathrm{m}$. 
a)

b)

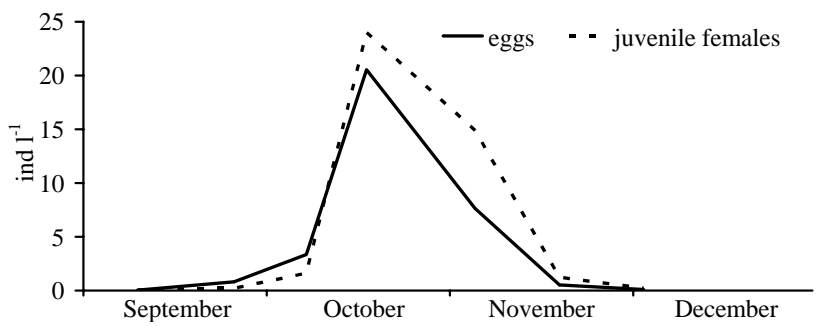

c)
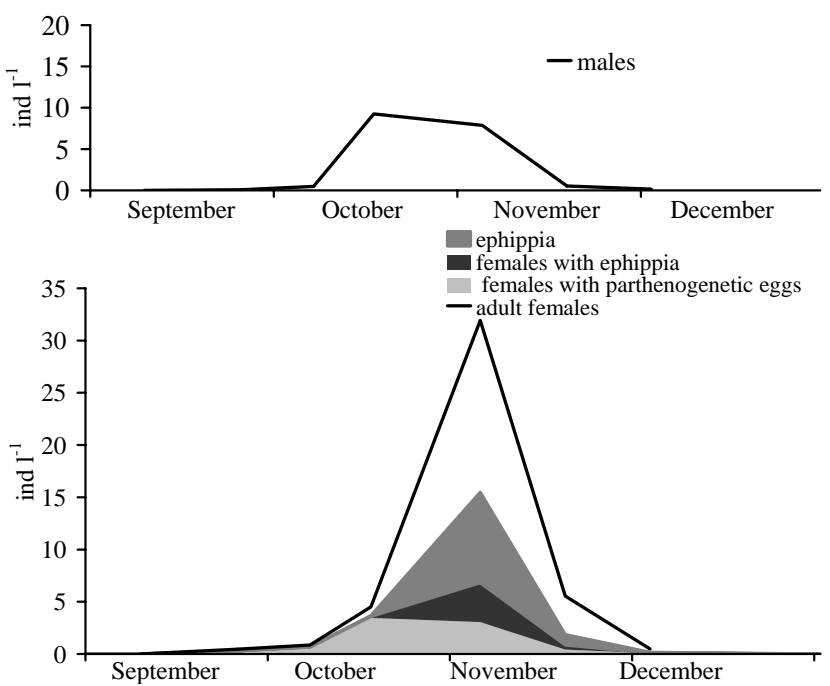

d)
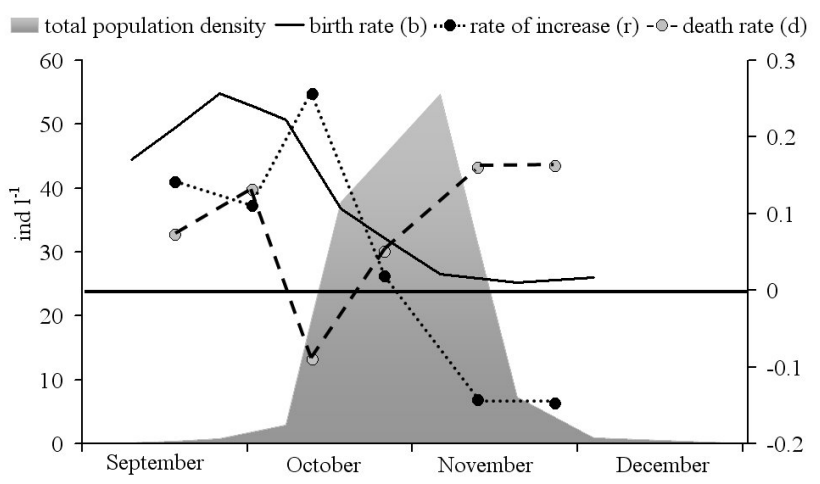

Fig. 2. Population structure of Daphnia parvula: a) eggs and juvenile females, b) males; c) parthenogenetic females, ephippial females, non ovigerous mature females and free ephippia; d) population parameters: instantaneous birth (b), growth (r) and death (d) rates.
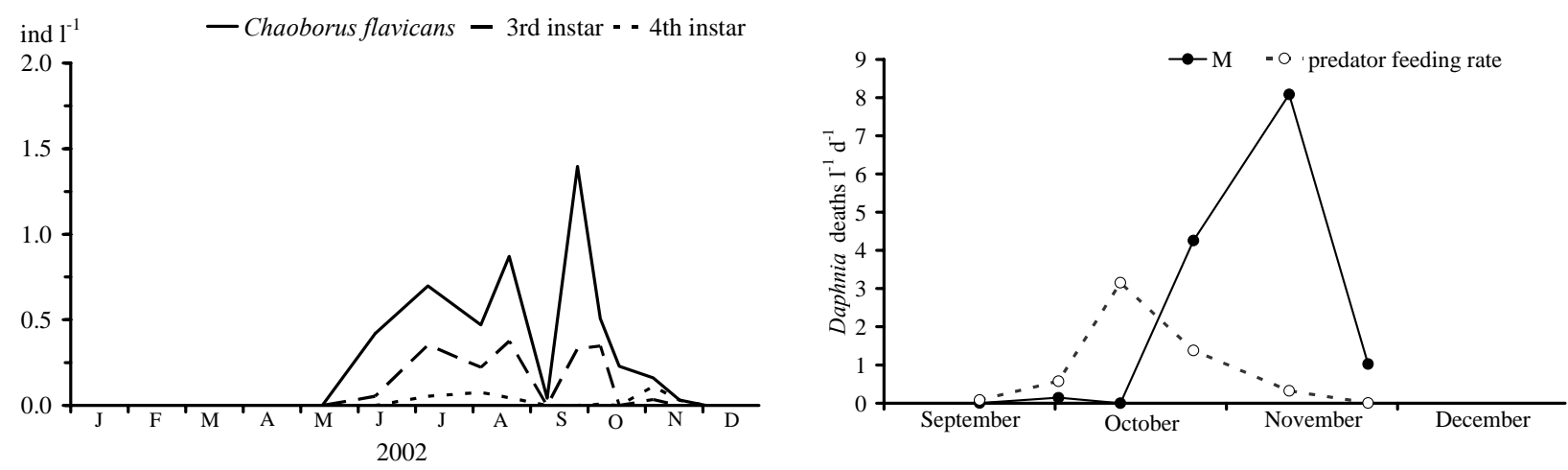

Fig. 3. Left panel, seasonal variation of of Chaoborus flavicans larvae in the water column and, right panel, Daphnia parvula daily mortality (M; $\mathrm{l}^{-1} \mathrm{~d}^{-1}$ ) and (estimated) Chaoborus population consumption rates (Daphnia consumed per liter per day). 

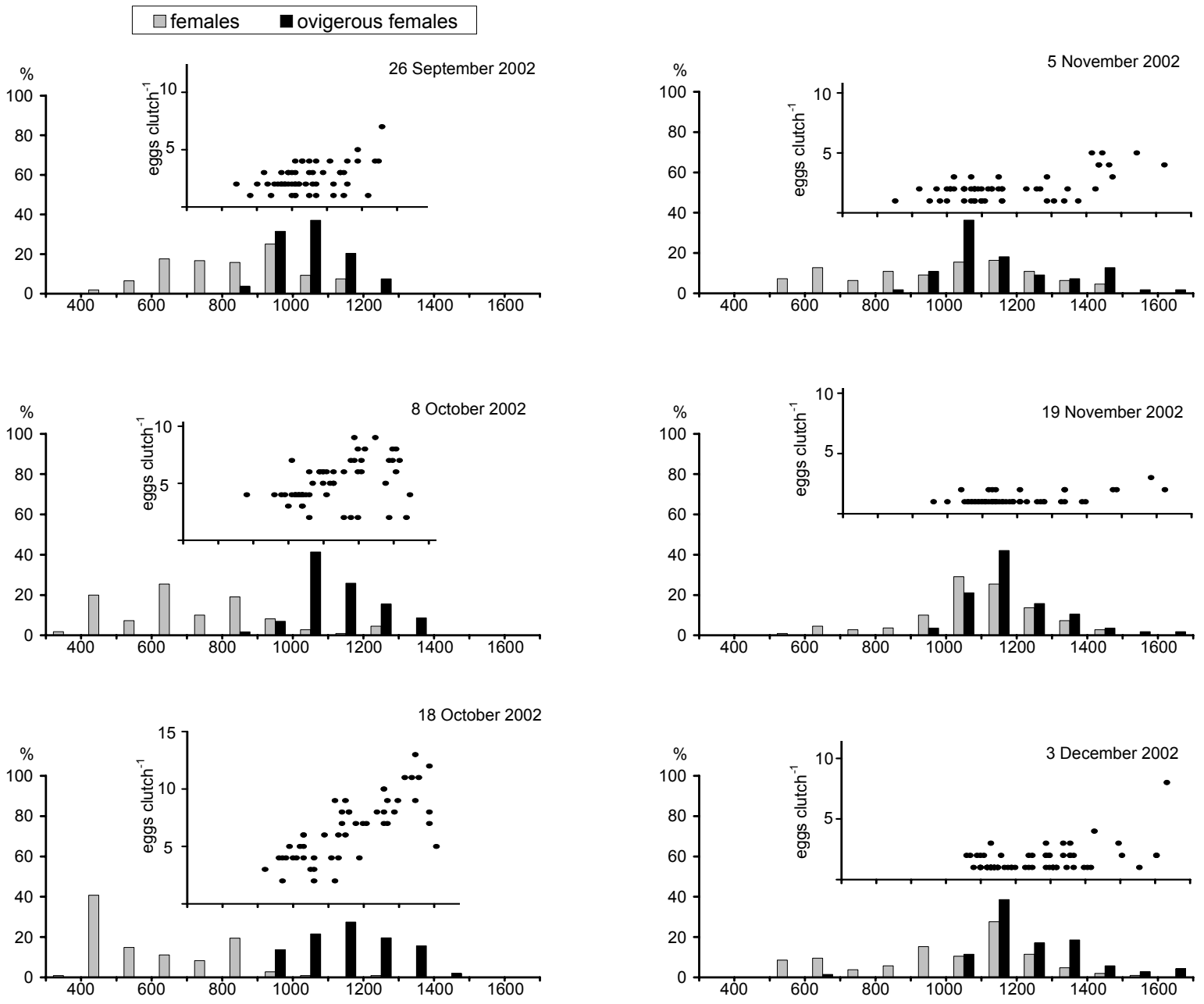

Fig. 4. Size-frequency distributions of Daphnia parvula females and relationships between clutch size (eggs clutch ${ }^{-1}$ ) and body length $(\mu \mathrm{m})$ for females bearing parthenogenetic eggs.

Later the population gradually shifted towards larger individuals, but the proportion of egg-bearing females in the mature classes decreased. Brood size increased with the mothers body length in September-October, while thereafter the number of eggs decreased and was not dependent on the size of the mother (Fig. 4).

The average size of reproductive females as well as their size at first reproduction (SFR) appeared to be negatively affected by temperature (Spearman $r=$ $0.964, p=0.003$; Spearman $r=-0,857, p=0.02$, respectively) (Fig. 5), while individual fecundity and egg ratio were positively correlated to chlorophyll concentration (Spearman $r=0.893, p=0.01$; Spearman $r=$ $0.964, p=0.003$ respectively) (Fig. 6, upper panel). Increases in the egg $\square$ population ratio before mid-October were due to increases in clutch size and in the proportion of egg bearing females (Fig. 6b) which preceded the maximum juvenile production. This resulted in a reduction of the egg ratio on October $18^{\text {th }}$, despite the fact that individual fecundity had further increased to its maximum. The peak of maximum population density reached on November $5^{\text {th }}$ marked the transition to a declining population mainly composed of larger females carrying fewer eggs (Fig. 4). The corresponding decrease in egg ratio reflected the reduction in both clutch size and the percentage of females with parthenogenetic eggs.

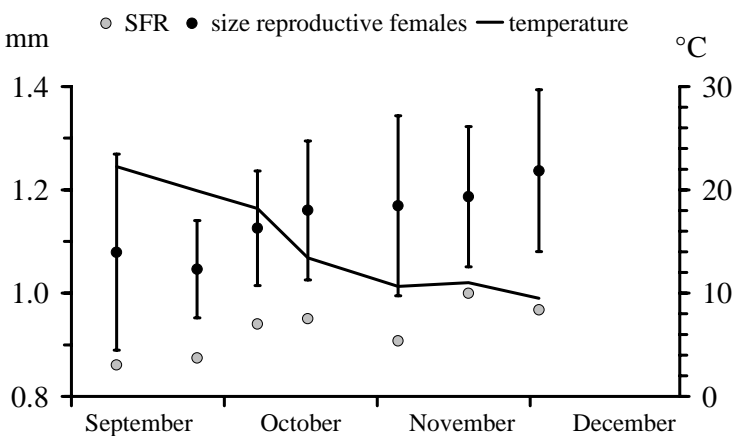

Fig. 5. Seasonal variation of temperature, average size of reproductive females and size at first reproduction. 
The production of males, which started at the onset of population growth, preceded ephippia formation, which increased from mid-October through November (Fig. 2c, Fig. 5b). The sex ratio ranged from 0.1 to 0.33 males per female, with a maximum on October $18^{\text {th }}$ when males accounted for as much as $24 \%$ of the total population density.

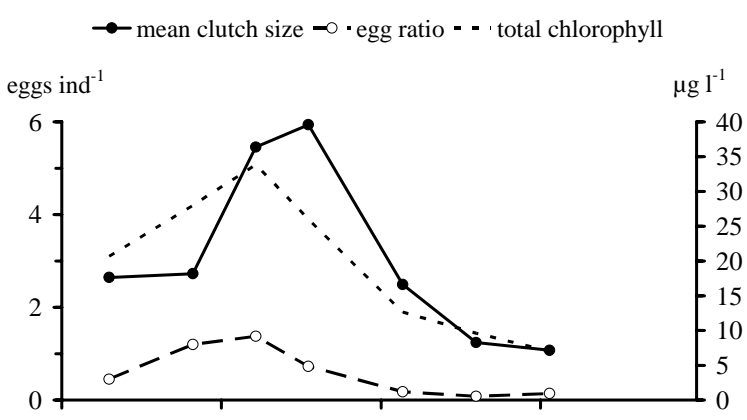

\% adult females $\square \%$ egg bearing females : :\% ephippial females

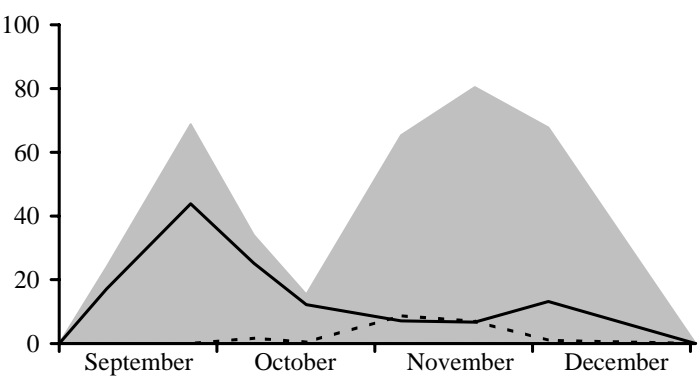

Fig. 6. Upper panel: variation in total chlorophyll concentration $\left(\mu \mathrm{g} \mathrm{l}^{-1}\right)$, mean clutch size (eggs clutch $^{-1}$ ) and egg ratio (eggs female $^{-1}$ ) for Daphnia parvula population. Lower panel: variation of population structure expressed as the percentage of adult and gravid females.

\section{DISCUSSION AND CONCLUSION}

According to Flössner (2000), D. parvula is typically found in meso-eutrophic waters, including shallow lakes, reservoirs, ponds, gravel pits and river meanders. It preferentially colonizes stagnant waters, where it takes advantage of the reduced competition to establish permanent populations.

The pattern of population dynamics of Daphnia parvula in Lake Candia showed three distinct phases, each lasting about one month. In the first phase, high birth rates were compensated for by relatively high death rates, probably due to juvenile (or egg) mortality. Predation by late instar larvae of Chaoborus flavicans may have contributed to juvenile mortality. However, competition with native Daphnia species, which were abundant in this period, seems to offer a more convincing explanation for the unrealized rate of increase at this early phase of invasion. Similarly, in a study on competitive interaction between Daphnia species, Johnson
\& Havel (2001) found that competitive suppression of D. parvula was expressed through depression of rates of increase, not by a depression of birth rates but from increased death rates. The exponential increase of $D$. parvula which immediately followed the decline of the native Daphnia populations seems to reflect a release from competition, and matches the hypothesis of a competitive suppression during September.

The maximum rate of increase $(r=0.256)$ measured in October at a temperature of about $16{ }^{\circ} \mathrm{C}$ was close to the values reported by Pace et al. (1984) for individuals reared in lake water at $20-25^{\circ} \mathrm{C}$. However, the species can attain higher rates of increase when reared in lake water enriched with a food surplus (Pace et al. 1984), and a value as high as 0.47 was measured in McDaniel Lake in June (Johnson \& Havel 2001). According to Pace et al. (1984), for a species like D. parvula which has relatively high growth rates $\left(r_{\max } \sim 0.4\right)$, age at first reproduction is the most significant factor determining $r$. However, in Lake Candia some other factors may have limited growth rates. Indeed, although the small size at first reproduction measured in September and October seems to indicate a rapid maturation of females, only $21 \%$ of the population was made up of parthenogenetic ovigerous females at the beginning of October. In the same period, the relatively high percentage (17\%) of males and sexual females in the population contributed to the reduction of the maximum potential rate of increase that $D$. parvula can attain. In fact, production of males began in a relatively early phase of population increase, and was followed by a shift to sexual reproduction of an increasing number of females as population density increased to its maximum. A large proportion of ephippia (3 to $23 \%$ of the total population density) were produced during most of the life cycle (October-November), corresponding to a huge energetic investment in sexual reproduction. This reproductive pattern seems to be quite unusual in the timing and duration of sexual reproduction and the proportion of energy switched from parthenogenetic to gametogenetic reproduction.

Both offspring sex and the appearance of sexual eggs are known to be determined in response to phenological and density dependent factors. Photoperiod, temperature, food quantity and quality, accumulation of metabolic products and increased encounter rate between females, chemical cues related to the presence and activity of predators are responsible for the induction of resting egg production (e.g. Carvalho \& Hughes 1983; Hebert 1987; Larsson \& Hobaek 1988; Kleiven et al. 1992; Slusarczyck 1995; Pijanowksa \& Stolpe 1996). Seasonal cues seem to have been more important than density dependent cues for the induction of $D$. parvula sexual reproduction in Lake Candia. In fact, both male and ephippia production began when population density was low and food was abundant enough to maintain relatively high individual fecundity. When the 
first ephippial females appeared at the beginning of October, the mean brood size of parthenogenethic females was $5.46 \pm 1.8$, a value close to the maximum (5.21 eggs/reproductive female) measured for $D$. parvula in Lake Oglethorpe (Orcutt \& Porter 1984), and intermediate compared to values measured in animals reared in lake water with and without food enrichment (Pace et al. 1984). According to Pace et al. (1984) the parthenogenetic population of Lake Oglethorpe is composed of different clones characterized by different life history traits which make them successful under different seasonal conditions. Resting egg formation occurring in spring and fall corresponds roughly to transitions in life history types. Conversely, in Lake Candia ephippia production lasted for two months, with a maximum corresponding to the population decline and disappearance before winter.

Very little information on European populations is available, and mostly describes morphological characteristics (e.g. Flössner \& Kraus 1976; Schrimpf \& Steinberg 1982; Schaber 1983; Petkowski 1990). Most of the studies in Europe deal with populations occurring in temporary ponds, pools, gravel pits and reservoirs, i.e. environments which are subject to periodical or occasional disturbance. Under these conditions the pattern of population density is likely to be driven by environmental disturbance, such as flooding or drying (e.g. Schrimpf \& Steinberg 1982), and it is reasonable to suppose that life history traits, including male and ephippia production, also reflect environmental bottlenecks. Although the study by Flössner \& Kraus (1976) on the first European populations established in Bavarian pools and gravel pits does not provide quantitative data and is not based on regular sampling, the presence of parthenogenetic females is documented from May to December, while males and sexual females occurred in October-November. From a three year study on a small lake in the Tyrol, Schaber (1983) observed that parthenogenetic females regularly appeared in June and increased until August, when males and ephippia were produced. The population which has been established in Lake Unterfranken for more than 15 years shows a maximum development in June-July and August-October, and declines in December after ephippia production (Flössner 2000).

All alien species can be expected, at least at the beginning of their naturalization, to show quite different life cycle patterns and population dynamics from those of populations in their native environments (e.g. Williamson \& Fitter 1996; Yan et al. 2001). Krylov \& Panov (1998) found that changes in the reproductive strategy of an invader population may result from different environmental cues received in the novel environment and could have adaptive value. While environmental differences as well as interaction with native species could explain variations in the seasonal cycle, some effect of genetic drift cannot be excluded. Nar- rower clone patterns existing in the alien population may explain differences in the timing and degree of resting egg production and hatching (e.g. Vanni 1987; De Meester \& De Jagher 1993; Pfrender \& Deng 1998; Alekseev \& Lampert 2001). It might also be the case that if population persistence over different seasons results from the succession or substitution of temporally specialized life history types, founder effects may result in the colonization of only some seasonal niches. However, this is only speculation.

Native Daphnia species typically persist in Lake Candia throughout the year with spring and autumn population maxima. After the introduction of E. gracilis in 1989, a trend towards a temporal shift of maximum Daphnia development consistent with the possiblity of niche segregation was observed. The introduction of $D$. parvula, which became common during a period of overlap with native Daphnia and E. gracilis, provides the potential for competition, which could modify the Daphnia-Eudiaptomus competitive equilibrium. The dominant role of Daphnia and Eudiaptomus from September to June means that any alteration of their cycles could have a major impact on the zooplankton assemblage. However, the small size of $D$. parvula, which lacks any kind of helmet or pointed crest, suggests that this species may be subject to preferential predation by Chaoborus flavicans, which could influence the outcome of competition with the native Daphnia.

\section{AKNOWLEDGMENTS}

We wish to thank all the colleagues who contributed to this research by providing their help for sampling and sample analysis (Gaetano Galanti, Igor Cerutti). A special thank is due to Victor Alekseev, Vadim Panov and Oscar Ravera for fruitful discussion of the results and the revision of an earlier draft of the manuscript. We are very grateful to Cecile and Jürgen Giese for translation of articles in German and to Sandra Spence for English revision.

\section{REFERENCES}

Alekseev, V. \& W. Lampert. 2001. Maternal control of resting-egg production in Daphnia. Nature, 414: 899-901.

Armengol, J. 1978. Los crustaceos de plancton de los emblases espanoles. Oecologia aquatica, 3: 3-96.

Bij de Vaate, A., K. Jazdzewski, H.A.M. Ketelaars, S. Gollasch \& G. Van der Velde. 2002. Geographical patterns in range extensio of Ponto-Caspian macroinvertebrate species in Europe. Can. J. Fish. aquat. Sci., 59: 1159-1174.

Bohonak, A.J. \& D.G. Jenkins. 2003. Ecology and evolutionary significance of dispersal by freshwater invertebrates. Ecology Letters, 6: 783-796.

Bollens, S.M., J.R. Cordell, S. Avent \& R. Hooff. 2002. Zooplankton invasions: a brief review, plus two case studies from the northeast Pacific Ocean. Hydrobiologia, 480: 87-110.

Caramujo, M.-J., M.C. Crispim \& M.-J. Boavida. 1997. Assessment of the importance of fish predation versus copepod predation on life history traits of Daphnia hyalina. Hydrobiologia, 360: 243-252. 
Carlton, J.T. 1996. Biological invasions and cryptogenic species. Ecology, 77: 1653-1655.

Carvalho, G.R. \& R.N. Hughes. 1983. The effect of food availability, female culture-density and photoperiod on ephippia production in Daphnia magna Straus (Crustacea, Cladocera). Freshwat. Biol., 13: 37-46.

Coussement, M.A., M. de Henau \& H.J. Dumont. 1976. Brachionus variabilis Hempel and Asplanchna girodi de Guerne, two Rotifer species new to Europe and Belgium respectively. Biol. Jb. Dodonaea, 44: 118-122.

De Meester, L. \& H. De Jager. 1993. Hatching of Daphnia sexual eggs. I. Intraspecific differences in the hatching responses of D. magna eggs. Freshwat. Biol., 30: 219-226.

Dzialowski, A.R., W.J. O'Brien \& S.M. Swaffar. 2000. Range expansion and potential dispersal mechanisms of the exotic cladoceran Daphnia lumholtzi. J. Plankton Res., 22: 2205-2223.

Ehrlich, P.R. 1986. Which animal will invade. In: Mooney, H.A. \& J.A. Drake (Eds), Ecology of Biological Invasions of North America and Hawaii. Springer-Verlag, New York: 79-95.

Einsle, U. 1978. Qualitative und quantitative Änderungen im Crustaceenplankton des Bodensee-Obersees. Arch. Hydrobiol., 82: 300-315.

Einsle, U. 1980. Weitere Untersuchungen (1976/77) über das Crustaceen-Plankton des Gnadensees (Bodensee_untersee). Schr. Ver. Gesch. Bodensees Umgeb., 98: 195-218.

Elton, C.S. 1958. The ecology of invasions by animals and plants. Methuen, London, U.K.

Figuerola, J. \& A.J. Green. 2002. Dispersal of aquatic organisms by waterbirds: a review of past research and priorities for future studies. Freshwat. Biol., 47: 483-494.

Flössner, D. \& K. Kraus. 1976. Zwei für Mitteleuropa neue Cladoceren-Arten (Daphnia ambigua Scourfield, 1946, und Daphnia parvula Fordyce, 1901) aus Süddeutschland. Crustaceana, 30: 301-309.

Flössner, D. 2000. Die Haplopoda und Cladocera (ohne Bosminidae) Mitteleuropas. Backhuys Publishers.

Frenzel, P. 1976. Nachweise zweier seltener Daphnia-Arten (Cladocera, Crustacea) in Südwestdeutschland. Mitt. Bad. Landesver. Naturk. Natursch. N.F., 11: 385-391.

Giussani, G. \& G. Galanti. 1995. Case study: Lake Candia (Northern Italy). In: de Bernardi, R. \& G. Giussani (Eds), Biomanipulation in Lakes and Reservoirs Management. Vol. 7. Guidelines of Lake Management. ILEC, UNEP: 135-146.

Giussani, G., de Bernardi, R. \& T. Ruffoni. 1990. Three years of experience in biomanipulating a small eutrophic lake: Lago di Candia (Northern Italy). In: Gulati, R.D., E.H.R.R. Lammens, M.-L. Mejier \& E. van Donk (Eds), Biomanipulation - Tool for Water Management. Hydrobiologia, 200-201: 357-366.

Grigorovich, I.A., R.I. Colautti, E.L. Mills, K. Holeck, A.G. Ballert \& H.J. MacIsaac. 2003. Ballast-mediated animal introductions in the Laurentian Great Lakes: retrospective and prospective analyses. Can. J. Fish. aquat. Sci., 60: 740-756.

Hebert, P.D.N. \& M.E.A. Cristescu. 2002. Genetic perspectives on invasions: the case of the Cladocera. Can. J. Fish. aquat. Sci., 59: 1229-1234.

Hebert, P.D.N. 1987. Genetics of Daphnia. In. Peters, R.H. \& R. de Bernardi (Eds), Daphnia. Mem. Ist. ital. Idrobiol., 45: 439-460.

Herbst, H.-V. \& D. Anders. 1987. Ein eingeschleppter Kleinkrebs (Crustacea, Cladocera) im Bergischen Land. Natur am Niederrhein, 2: 26-30.

Holling, C.S. 1959. The components of predation as revealed by a study of small-mammal predation of the European pine sawfly. Can. Entomol., 91: 293-320.
Hrbáček, J. 1987. Systematics and biogeography of Daphnia species in the northern temperate regions. In: Peters, R.H. \& R. de Bernardi (Eds), Daphnia. Mem. Ist. ital. Idrobiol., 45: 37-76.

Jarnagin, S.T., B.K Swan. \& W.C. Kerfoot. 2000. Fish as vectors in the dispersal of Bythotrephes cederstroemi: diapausing eggs survive passage through the gut. Freshwat. Biol., 43: 579-589.

Johnson, L.E., A. Ricciardi \& J.T. Carlton. 2001. Overland dispersal of aquatic invasive species: a risk assessment of transient recreational boating. Ecological Applications, 11: 1789-1799.

Johnson, J.L. \& J.E. Havel. 2001. Competition between native and exotic Daphnia: in situ experiments. J. Plankton Res., 23: 373-387.

Kleiven, O.T., P. Larsson, \& A. Hobæk. 1992. Sexual reproduction in Daphnia magna requires three stimuli. Oikos, 65: 197-206.

Krylov, P.I. \& V.E. Panov. 1998. Resting eggs in the life cycle of Cercopagis pengoi, a recent invader of the Baltic Sea. Arch. Hydrobiol. Spec. Issues Advanc. Limnol., 52: 383-392.

Krylov, P.I. 1992. Density-dependent predation of Chaoborus flavicans on Daphnia longispina in a small lake: the effect of prey size. Hydrobiologia, 239: 131-140.

Larsson, P. \& A. Hobæk. 1988. Production of males in daphnids. Verh. int. Ver. Limnol., 23: 2062.

McMahon, R.F. 2002. Evolutionary and physiological adaptations of aquatic invasive animals: $r$ selection versus resistance. Can. J. Fish. aquat. Sci., 59: 1235-1244.

Orcutt, J.D. \& K.G. Porter. 1984. The synergistic effects of temperature and food concentration on life history parameters of Daphnia. Oecologia (Berlin), 63: 300-306.

Pace, L.M., K. Porter \& Y.S. Feig. 1984. Life history variation within a parthenogenetic population of Daphnia parvula (Crustacea: Cladocera). Oecologia (Berlin), 63: 43-51.

Paloheimo, J.E. 1974. Calculations of instantaneous birth rate. Limnol. Oceanogr., 19: 692-694.

Panov, V.E., P.I. Krylov \& N. Riccardi. (2004). Role of diapause in dispersal and invasion success by aquatic invertebrates. In: Alekseev, V., R. de Bernardi \& O. Ravera (Eds), Diapause in aquatic invertebrates. Proc. Workshop held in Pallanza on 21-23 October 2003. J. Limnol.: (in press).

Petkovski, S.T. 1990. Nachweise von Daphnia pulicaria Forbes, 1893 emend. Hrbáček (1959) und Daphnia parvula Fordyce, 1901 in Jugoslawien (Crustacea, Cladocera, Anomopoda). Mitt. Hamb. Zool. Mus. Inst., 87: 261-272.

Pfrender, M.E. \& H.W. Deng. 1998. Environmental and genetic control of diapause termination in Daphnia. Arch. Hydrobiol. Spec. Issues Advanc. Limnol., 52: 237-251.

Pijanowska, J. \& G. Stolpe. 1996. Summer diapause in Daphnia as a response to the presence of fish. J. Plankton Res., 18: 1407-1412.

Pimm, S.L. 1989. Theories of predicting success and impact of introduced species. In: Drake, J.A., F. DiCastri, R.H. Groves, F.J. Kruger, H.A. Mooney, M. Rejmanek \& M.H. Williamson (Eds), Biological Invasions: a global perspective. Wiley and Sons, New York, New York, USA: 351-368.

Riccardi, N., G. Giussani \& L. Lagorio. 2002. Morphological variation and life history changes of a Daphnia hyalina population exposed to Chaoborus flavicans predation (L. Candia, Northern Italy). J. Limnol., 60: 41-48.

Saunders, P.A., K.G. Porter \& B.E. Taylor. 1999. Population dynamics of Daphnia spp. and implications for trophic interactions in a small, monomictic lake. J. Plankton Res., 21: 1823-1845.

Schaber, P. 1983. Erstnachweis von Daphnia parvula Fordyce 1901 in Tirol (Oesterreich) (Crustacea, Cladocera). Ber. Nat. - Med. Verein Innsbruck, 70: 61-66. 
Schrimpf, A. \& C. Steinberg. 1982. Weitere Fundorte der für Süddeutschland neu nachgewiesen Cladocere Daphnia parvula Fordyce 1901 (Crustacea, Phyllopoda). Arch. Hydrobiol., 94: 372-381.

Shurin, J.B. 2000. Dispersal limitation, invasion resistance, and the structure of pond zooplankton communities. Ecology, 81: 3074-3086.

Slusarczyck, M. 1995. Predator-induced diapause in Daphnia. Ecology, 76: 1008-1013.

Vanni, M.J. 1987. Colonization dynamics and life history traits of seven Daphnia pulex genotypes. Oecologia (Berlin), 72: 263-271.

Vitousek, P.M. 1986. Biological invasions and ecosystem properties: Can species make a difference? In: Mooney, H.A. \& J.A. Drake (Eds), Ecology of Biological Invasions

Received: October 2003

Accepted: January 2004 of North America and Hawaii. Springer-Verlag, New York: 163-177.

Vitousek, P.M., C.M. D'Antonio, L.L. Loope \& R. Westbrooks. 1996. Biological invasions as global environmental change. Am. Sci., 84: 468-478.

Williamson, M. \& A. Fitter. 1996. The varying success of invaders. Ecology, 77: 1661-1666.

Work, K.A. \& M. Gophen. 1999. Environmental variability and the population dynamics of the exotic Daphnia lumholtzi and native zooplankton in Lake Texoma, U.S.A. Hydrobiologia, 405:11-23.

Yan, N.D., A. Blukacz, W.G. Sprules, P.K. Kindy, D. Hackett, R.E.Girard \& B.J.Clark. 2001. Changes in zooplankton and the phenology of the spiny water flea, Bythotrephes, following its invasion of Harp Lake, Ontario, Canada. Can. J. Fish. aquat. Sci., 58: 2341-2350. 